\title{
Public-Private Partnerships for Sustainable Development: Exploring Their Design and Its Impact on Effectiveness
}

\author{
Axel Marx \\ Leuven Centre for Global Governance Studies, University of Leuven, 3000 Leuven, Belgium; \\ axel.marx@kuleuven.be
}

Received: 14 February 2019; Accepted: 18 February 2019; Published: 19 February 2019

check for updates

Public-private partnerships for sustainable development have been in operation for several decades from the local to the international level. On the one hand they are a result of a changing nature of public policy-making. This is captured by the so-called shift from 'government' to 'governance', signaling that governments are no longer the only providers of public policy but increasingly engage private actors [1]. In this type of public-private partnerships private actors are involved in one or more of the different steps or parts of policy-making: agenda-setting, negotiation, resource provision implementation, monitoring, and/or enforcement. In this type of public-private partnerships a key policy function is delegated to private actors. One could argue that this form of public-private partnerships is still hierarchical and dominated by public policy-makers. Private actors perform functions which public actors cannot do or which private actors perform more efficiently. This form of public private partnerships complements more traditional forms of command and control policies. On the other hand, one observes the emergence of a new type of public-private partnerships in which autonomous public or private policy instruments are combined in new governance structures and arrangements. This is more a collaborative form of governance which is less structured and steered and in which autonomous policy-actors combine forces on all components of the policy-process [2-4]. This goes beyond the typical service provision private actors perform in the first type of public policy-making.

With the adoption of the 2030 Agenda for Sustainable Development and the Sustainable Development Goals (SDGs) public-private partnerships have become even more prominent. The UN agenda is a plan of action for 'people, planet, and prosperity'. The 17 Goals cover all crucial policy areas to secure a sustainable future including education, health, economic development, social protection, environmental protection, and natural resources governance. The 17 goals are operationalized in 169 targets which need to be reached by 2030 or earlier. The SDGs build on the Millennium Development Goals and aim to complete what these Millennium Development Goals did not achieve. A crucial difference between the Millennium Development Goals and Sustainable Development Goals is that the former were mainly targeted to governments while the latter target many different stakeholders including the private sector. Indeed, a shift in approach between the Millennium Development Goals and the Sustainable Development Goals is the recognition that policy objectives are best achieved by involving and integrating private actors in the policy process.

Private actors may contribute significantly towards achieving the SDGs by providing resources, expertise and knowledge, implementation and enforcement capacity, and legitimacy [5]. The United Nations and the international community recognize explicitly that achieving sustainable development will not be possible without the involvement of private sector and public-private partnerships. Currently more than 4000 partnerships are recognized and linked to one SDG or more SDGs. The effectiveness of these public-private partnerships will be crucial to achieve the SDGs. One factor which determines the effectiveness of public-private partnerships is the institutional design of these 
partnerships. Institutional design is defined as the rules establishing and governing an interaction between actors in a collaborative setting to achieve a specific policy goal. Significant research focuses on the design of how policy objectives are determined (agenda-setting and negotiation, monitored, implemented, and enforced) [5-7].

Another aspect of institutional design which is especially relevant for public-private partnerships focuses on how the partnerships themselves are designed. Several researchers have made databases on public-private partnerships and provided an aggregate picture of the different types of partnerships, the issues on which they focus, and the partners involved [8,9]. Less attention has focused on the different design components which are relevant in the context of a specific partnership or set of partnerships. Which actors are involved, do private actors contribute significantly to policy outcomes, does the integration of private actors in the policy process possibly create unintended effects, how are relationships between actors in a public-private partnership governed, etc. are all questions which are open to investigation and debate.

This special issue aims to identify some key insights into these questions and in how public-private collaboration for sustainability operates across the globe. The response to the call for papers resulted in a diverse set of papers which capture different ways in which public and private actors interact and how the partnerships are designed. It is interesting to observe that there seems to be distinct approaches towards public private partnerships in Europe and Asia. Four contributions focus on public-private partnerships in Asia and mainly in China. In these public-private partnerships the design is very much driven by government which integrates private components to implement policies or provide resources. In this approach private actors are brought in the policy-making process for cost-efficiency reasons or for effectiveness reasons. The papers which discuss European examples of public-private partnerships focus more on the discrete contribution private actors can make, in complementarity with public actors, to pursue sustainable development. Here, private actors might engage public actors to achieve their results.

A common thread through all contributions is that they focus on the design of the public-private partnerships and how that might relate to their performance and effectiveness. Effectiveness in this context can be operationalized on multiple dimensions. Effectiveness can refer to impact on the ground of certain projects and initiatives to reach specific policy goals (goal-attainment effectiveness, i.e. contributions by Yang; Zheng et al.; Franssen et al., and Ingram et al. this volume), lead to increased adoption of private governance mechanisms scaling up their potential impact (process-effectiveness, Marx this volume) or contribute to an increase in recognition of certain public-private initiatives as the most appropriate governance approach to address certain policy issues (constitutive effectiveness, i.e., Tellbro et al., Martens et al.; Moratis; Schouten, and Hospes this volume).

This focus on institutional design and its relationship to effectiveness builds on a longstanding stream of research which was pioneered by Elinor Ostrom [10] and further developed by 'institutional scholars'. In this volume, we focus on different aspects of design, both in terms of substance as well as procedures. In terms of substance the focus is on the degree to which public-private initiatives really take sustainability concerns, in all their dimensions, into consideration. In procedural terms, the focus is on which rules govern the design of public-private partnerships in order to make them more effective. Most contributions in the special issue focus on these procedural aspects in order to identify what works or not. Taken together, the different contributions identify several key-factors which contribute to the potential of public-private partnerships to address sustainability challenges.

A first important issue in the design of public-private partnerships is the degree to which they integrate sustainability concerns in their operations. For several initiatives this sustainability focus is the core reason for their existence and hence in these cases this is not much of an issue since their establishment is enshrined in the idea of sustainability. However, in several cases existing public-private partnerships have increasingly had to integrate sustainability concerns. If they do this insufficiently it is difficult to achieve sustainability results in the first place. This issue is explored in the paper by Cheng Chen, Dan Li and Caixia Man (Toward Sustainable Development? A 
Bibliometric Analysis of PPP-Related Policies in China between 1980 and 2017). They provide a quantitative bibliometric analysis of 299 PPP-related policy documents issued by the Chinese central government between 1980 and 2017. They develop a framework to analyze the sustainability components of these policy documents. Sustainability is operationalized along the three traditional dimensions of ecological sustainability, social sustainability, and financial sustainability. The bibliometric analysis is conducted on policy documents which contained information about the date, title, policymaking departments, content, and effective status of the policies at issue. The paper identifies three distinct historical phases in PPP development and the role of sustainable development therein: Phase I (1980-1997), the encouragement of foreign investment in the public infrastructure, Phase II (1998-2008), the encouragement of the marketization of the urban public utilities, and Phase III (2009-2017), the intensive institutionalization and extensive application of PPPs for solving the local debt problem. Corresponding to the abovementioned policy priorities, this article finds that the pattern of PPP-related policies has shifted from the total absence of sustainable development policies in Phase I, to a few sustainable development policy attempts in Phase II, and finally, to a tendency toward policies favoring sustainable development in Phase III. It emerges that the principles of sustainable development, rather than being treated as the ultimate goals, are the side products of PPP-related policies that are aimed to achieve economic development and public financial problem-solving. Therefore, it is suggested that, in terms of establishing sustainable development as the core value of PPPs, a fundamental change in the understanding of PPPs as governance scheme rather than a pragmatic economic tool is required.

A second design factor concerns who is involved in public-private partnerships. A first question to address is whether it is always advisable to include private actors in the design of policy instruments to achieve sustainability goals. Two papers generate insights on this question. The paper by Chia-Lee Yang, Ming-Chang Shieh, Chi-Yo Huang, and Ching-Pin Tung, (A Derivation of Factors Influencing the Successful Integration of Corporate Volunteers into Public Flood Disaster Inquiry and Notification Systems) aims to identify the factors enabling corporate volunteers to respond to inquiries and notify the public disaster management system of flood disasters, which represent an important issue for sustainable development and require current and accurate information. This paper investigates whether systems which use private actors in monitoring and implementation perform better than systems which do not include private actors. The authors add the private and public-private dimension, defined as the collaboration between a public sector entity and a private sector entity to achieve a specific goal or set of objectives, as one of the influencing dimensions. The paper uses a number of data sources and data collection techniques and applies their framework to flood disaster notification systems in Taiwan. Experts were asked to identify possible factors enabling corporate volunteers to provide information to the flood disaster inquiry and notification system and the validity of the results were further confirmed by summarizing opinions provided by other experts. It emerged that systems which included private actors did not perform better and the integration of private actors in the design of policies only ranked low as a key component for performance. Also the systems which integrated private actors required more resources and hence were not more cost-efficient. This contribution shows that linking private and public actors is not always the most cost-efficient or effective way to achieve policy objectives.

A second paper on the integration of private actors in public policies is provided by Axel Marx on Integrating Voluntary Sustainability Standards in Trade Policy: The Case of the European Union's GSP Scheme. He investigates whether private governance instruments can play a role in addressing compliance gaps in public policy-making by focusing on a specific case study in EU trade policy. Trade policy is increasingly being used as a policy instrument to pursue non-trade objectives, such as environmental protection or the protection of labor rights. The paper investigates the potential role that Voluntary Sustainability Standards (VSS) can play in addressing current compliance gaps in the European Union's Generalized Scheme of Preferences (GSP). GSP is a preferential trade arrangement by which the EU grants unilateral and non-reciprocal preferential market access to goods originating in developing countries. VSS could be integrated in GSP in two ways. The first option is to allow access to the European market if products comply with VSS standards. The second option is to give tariff preferences 
(lower tariffs or elimination of tariffs) to VSS certified products. The overall conclusion of the paper is that it might be difficult to integrate the VSS in EU trade policy. The integration of the VSS in EU trade policy might negatively affect the utilization rate of GSP, which would result in a lesser use of GSP, and hence defeat the objectives on which GSP is built. This analysis shows that integrating private actors in public policy might create trade-offs. It might result in the fact that the private governance instruments are more adopted, but it might defeat the objectives of public trade policy due to a lower use of a specific trade instrument. This paper illustrates some of the limitations of integrating private mechanisms in public policies in the case of trade policy.

Also linked to the debate on the integration of private actors in public-private partnerships is the question of how inclusive public-private partnerships are in relation to the private actors who are involved in the partnerships. This issue is addressed in the paper by Deborah Martens, Annelien Gansemans, Jan Orbie, and Marijke D'Haess (Trade Unions in Multi-Stakeholder Initiatives: What Shapes Their Participation?). They examine the determinants that enable and constrain trade union participation in multi-stakeholder initiatives (MSIs) designed to improve social and environmental sustainability in global supply chains. For this purpose, the authors develop an analytical framework that takes into account both the structure of the MSI as well as the agency of the participant. Based on interviews, focus groups, observations, and document analysis the authors determine local trade union participation in three MSIs, operating at company, national, and transnational level respectively, in the Costa Rican pineapple industry. The interdisciplinary research presented in this paper is based on 37 semi-structured interviews with various actors from different stakeholder categories, three focus groups with trade union members, eight non-participant observations missions, and document analysis. Extensive field research was conducted in Costa Rica (2015-2016) with Costa Rican representatives and in Belgium (2015-2017) with EU representatives. These two rounds of data collection were followed-up by interviews in 2018 to collect additional information on the concerned multi-stakeholder initiatives for this case study. The findings endorse the concern that MSIs are not as inclusive as they aspire or pretend to be. Physical attendance does not necessarily imply participants will be heard. To achieve a better quality of participation and deliberation, power inequalities among its participants should be addressed by improving MSI design. First, the selection criteria for participation to the MSI should be clearly predefined and ensure the representativeness of the participants. Stakeholders should be identified together with a mapping of potential conflicts, expectations, and their power resources. Second, regarding procedural fairness, clear goals and rules of decision-making should be set from the start and agreed by all stakeholders, stronger and weaker stakeholders alike. Third, concerning the consensual orientation in MSIs, the authors see that building trust between actors with divergent positions is challenging. Therefore, the format of MSIs should recognize existing power differences and facilitate a rapprochement between business and unions, for example through small working groups and capacity-building events. The analysis also indicates that the design of an MSI is not all-decisive as insights on trade union power resources also helped to explain their participation. Also strong network embeddedness and improved infrastructural resources enhanced trade union participation, whereas the lack of internal solidarity and unfavorable narrative resources had a negative effect on their participation. This implies for practitioners involved in MSIs that improving the design of MSIs is necessary but not sufficient to enhance trade union participation. Unions need to mobilize their resources and the willingness and commitment of all participants in the MSI to meaningfully engage in deliberation. The authors call for a continuous evaluation of MSI participatory processes (regarding representativeness, procedural fairness, and consensual orientation) and strengthening of union power resources (internal solidarity, network embeddedness, narrative and infrastructural resources). From an institutional design perspective this paper clearly shows how design is influenced by dynamics in the partnership as well as dynamics within one partner in the partnership. In order to achieve inclusiveness, partnerships have to develop a clear strategy which also provides incentives for specific actors to join in. 
The latter, the incentives and motivational aspects of private actors to engage in public private partnerships is further explored by Shengqin Zheng, Ke $\mathrm{Xu}$, Qing He, Shaoze Fang, and Lin Zhang (Investigating the Sustainability Performance of PPP-Type Infrastructure Projects: A Case of China). They focus on the proliferation of public-private partnership (PPP) in China. Their focus is less on the implementation part of policies and more on agenda-setting and revenue-generation to facilitate policy-making. PPPs, as an innovative procurement mode, have been playing a vital role in developing public infrastructures in China. The demand for public infrastructure is continuously increasing due to the acceleration of urbanization and the rapid growth of the economy. Faced with the shortage of funds, governments are compelled to seek cooperation from private sectors who can provide a large number of funds, to participate in public infrastructure construction. As a result, PPP has experienced a rapid expansion and a boom period for the last five years in China. However, the authors argue that a series of social issues arise when an increasing number of PPPs are applied in infrastructure development due to profit-seeking behavior of private actors. As a result the paper aims to understand whether and how behaviors of private actors in PPPs influence the execution of the project with specific attention towards sustainability concerns. They show that there might be serious sustainability concerns in the current PPPs approach in infrastructure development and provide a series of suggestions, both to governments and private actors, on how to address them.

Besides the issue of which actors are involved in the public-private partnership, their interrelation is also important, and constitutes a third design component. By engaging in public-private partnerships actors develop relations which will influence the outcome of their collaboration. Several papers engage on this issue.

First, there is the issue of how the partnership is governed and who takes the lead. Camilla Thellbro, Therese Bjärstig, and Katarina Eckerberg (Drivers for Public-Private Partnerships in Sustainable Natural Resource Management-Lessons from the Swedish Mountain Region) focus on environmental partnerships which aim to improve the environmental quality or natural resource utilization. They are especially interested in factors contributing to the success of PPPs with a specific focus on leadership, incentives, and previous projects. The authors examine the shaping of participation, leadership, and the implementation of partnering processes on natural resource management of environmental PPPs in the Swedish mountain region. This study builds upon 38 semi-structured interviews with representatives from environmental PPPs in the Swedish mountain region randomly selected from a database of 245 public-private collaborative projects. The interviews were compiled according to contextual variables and four essential drivers: leadership, consequential incentives, interdependence, and uncertainty. Leadership refers to a present and identified leader who holds a position that allows him/her to initiate and aid in securing resources and support for a collaborative arrangement; consequential incentives are positive or negative incentives that make leaders and participants engage collectively; interdependence is the driver when individuals and organizations cannot achieve their objectives on their own; uncertainty can drive parties to collaborate in order to reduce, spread, and share risk(s). This case study of the Swedish mountain region shows that the mountain municipalities have an important facilitating role with regard to the leadership driver. Furthermore, the authors identified consequential incentives as being a major driver for most of the PPPs, where funding, a previous successful collaboration, and the presence of an issue/area that otherwise would not be handled stood out as the main reasons. Shared engagement and responsibility were also put forward by the respondents to some extent, suggesting that interdependence and uncertainty are indeed important drivers, but often function as intermediate drivers and/or in combination with the two main drivers: leadership and consequential incentives.

Second, there is the issue of the nature of the relationship between the actors and how that influences the performance of public-private partnerships. The paper by Xiaodan Zheng, Jingfeng Yuan, Jiyue Guo, Mirosław J. Skibniewski, and Sujun Zhao (Influence of Relational Norms on User Interests in PPP Projects: Mediating Effect of Project Performance) focuses on how mutual relations relate to performance and effectiveness. Using a sample of 109 questionnaires from Chinese project professionals 
who had experience with public-private partnership projects, this paper examines the relationships between the public and private actors, the norms shaping this relation (flexibility, information exchange and solidarity) their impact on project performance and how they shape the interests of different users of public-private partnership projects. The results show that relational norms between the public and private sectors had a positive relationship with project performance, and project performance could facilitate the protection of the interests of different users. The different dimensions of the relational norms between actors all contribute towards improving project performance. This is because the public and private sectors can flexibly adjust to changing environmental conditions, can share information to reduce mutual suspicion and conflicts, and can make decisions based on project interests rather than self-interest. As a result, good relational norms between private and public actors can have a direct positive effect on user interests through improving project performance. The argument is further substantiated by a specific case study which focuses on the Hong Kong Western Harbor Tunnel PPP project.

This focus on trust underlying actor relationship has been long established in the literature on inter-organizational cooperation [11]. This is a very important aspect of relationships in public-private partnerships since partners are of a very different nature. Continued support by public actors might make the public-private partnership more effective. Greetje Schouten and Otto Hospes (Public and Private Governance in Interaction: Changing Interpretations of Sovereignty in the Field of Sustainable Palm Oil) analyze how states that are connected to different positions of a global value chain interpret sovereignty over a longer period of time in their interactions with transnational private governance. The paper focuses on the interactions of Indonesian and Dutch state actors with the Roundtable on Sustainable Palm Oil (RSPO), which is a global private governance initiative that developed sustainability standards for the palm oil industry. Indonesia was selected as it is the biggest palm oil producer in the world, and the Netherlands, as the biggest importer of palm oil in Europe. Schouten and Hospes identify two distinctive episodes in which the type of interactions taking place between the Indonesian or Dutch state actors and the RSPO shifted significantly. The first episode took place during the rule formation process of the RSPO (2003-2009). During this time, the Indonesian government was willing to share the control of cross-border flows of palm oil with a private regulatory arrangement and implicitly practiced a notion of interdependence sovereignty, in which state and non-state actors shared control over cross-border flows of goods. In this first time lapse also the Dutch government used and interpreted sovereignty in the same ways as the Indonesian one and the RSPO was seen as sovereign over the global palm oil value chain. The second episode started with the announcement and development of a national Indonesian standard: the Indonesian Sustainable Palm Oil (ISPO) standard (2010-2017). The Indonesian government explicitly distanced itself from the RSPO and established a competing sustainability standard. The changing nature of the interactions indicates that the notions of interdependence sovereignty have faded, and have been replaced by notions of domestic and Westphalian sovereignty: the Indonesian government no longer wants to share sovereignty over the sustainability of palm oil that is produced on its territory. To the contrary, the Dutch government maintained its collaborative and supportive attitude toward the RSPO, assuming that a sustainable palm oil supply chain for the world can only be achieved if all of the public and private stakeholders work together in a coherent way according to each role and responsibility. The paper shows that sovereignty is not a static concept; instead, it is used strategically by different state actors and its use changes over time. When the Indonesian government realized that the RSPO might actually hamper the economic interests of Indonesian producers, they began to interact differently with the RSPO and started to develop a national standard. The development of rival standards by producing countries may create a further differentiation and fragmentation of the governance of sustainable agricultural commodities, especially when consuming states focus solely on promoting private voluntary standards. Aligning the public strategies of different countries and private strategies with one another might increase regulatory coherence to increase sustainable practices in global value chains. 
This 'relational' component of institutional design focuses on the relationship between actors 'within' a partnership. There is a third component of the institutional design which looks at how the partnership interacts with other actors, mainly the object or target of their initiative. In regulatory governance this is often referred to as the rule-taker. Different types of relationships can unfold between the partnership and the rule-taker depending on the perceived effectiveness of the partnership. This is explored in two papers, which provide for a rule-takers perspective. In a first paper, Lars Moratis (Signalling Responsibility? Applying Signalling Theory to the ISO 26000 Standard for Social Responsibility) starts from the observation that voluntary standards involving governments, non-governmental organizations, and companies have gained much traction in recent years and from a firm perspective, sustainability standards can be a way to demonstrate that they engage in corporate social responsibility (CSR) in a credible way. To capitalize on their CSR activities, firms need to ensure their stakeholders are able to recognize and assess their CSR quality. However, because the relative observability of CSR is low and since CSR is a contested concept, information asymmetries in a firm-stakeholder relationship arise. Adopting CSR standards and using these as signaling devices is a strategy for firms to reduce these information asymmetries, by revealing their true CSR quality. This paper investigates the voluntary ISO 26000 standard for social responsibility as a form of public-private governance and contends that, despite its objectives, this standard suffers from severe signaling problems. By applying signaling theory to the ISO 26000 standard, this article takes a critical stance towards this standard and argues that firms adhering to this standard may actually emit signals that compromise rather than enhance stakeholders' ability to identify and interpret firms' underlying CSR quality. Moratis concludes that firms, their stakeholders, governments, and organizations involved in the standardization of business conduct should be aware of the signals firms emit by ISO 26000 in order to not let the standard become part of the problems it set out to solve and exacerbate rather than reduce problems in public-private governance.

The second paper by Verina Ingram, Fedes van Rijn, Yuca Waarts, and Henk Gilhuis (The Impacts of Cocoa Sustainability Initiatives in West Africa) looks at the social, economic, and environmental effects of public-private-civil society partnerships of stakeholders, which try to implement voluntary sustainability standards and corporate initiatives in the cocoa sector. They focus on the 'rule-takers' in the cocoa sector. The paper is based on empirical evidence from large-scale, mixed-method studies using a suite of socioeconomic, agronomic, and environmental indicators to compare the situation of UTZ certified with non-certified farmers in 2012 and 2015 in Ghana, and 2013 and 2017 in Ivory Coast. The UTZ standard focuses on mainstreaming sustainability in farming practices, promoting the improvement of farmer's agricultural and management practices, with a chain of custody approaches, traceability, and transparency reflecting concerns by consumers and NGOs about chain governance. Seven of the main trader-exporters and processors in West Africa have adopted UTZ and, often, a second certification scheme. The study uses a large sample of stakeholders in the two largest cocoa producing countries, rigorous quantitative and qualitative methods to investigate the impacts of voluntary certification, and the related package of services, to understand what has been the impact of sustainability-focused interventions on cocoa farmers in West Africa. To analyze the contribution of sustainability initiatives to farmer livelihoods, panel data were collected from over 778 cocoa farming households in Ghana and the Ivory Coast between 2012 and 2017 and 18 focus group interviews with farmers, and 22 interviews with other stakeholders in the value chain were conducted. Two rounds of farmer household surveys were implemented in each country among UTZ and non-certified farmers. The results show that, on average, outcomes are mixed and generally modest. However, significant cocoa productivity and income increases were experienced by certified farmers receiving a full package of services. However, the type and intensity of services have changed over time, decreasing for half of the farmers, and productivity and income increases are leveling off. These findings suggest that whilst partnerships have created new governance arrangements with an increased focus on sustainable value chains, initiatives which result in a living income and optimize productivity, whilst limiting 
environmental impacts, require sectoral transformation, continued partnerships, plus a range of other policy instruments to address the persistent problems in cocoa production.

Finally, on the topic of inter-organizational relations between public and private actors it is also interesting to analyze how they interact on a more aggregate level, i.e. in a more wide and complex network of international actors which aim to address global public policy objectives such as environmental protection. This is precisely the focus of the paper by Luc Fransen, Jelmer Schalk, Marcel Kok, Vivek Voora, Jason Potts, Max Joosten, Philip Schleifer, and Graeme Auld on (Biodiversity Protection through Networks of Voluntary Sustainability Standard Organizations). They investigate the degree to which Voluntary Sustainability Standard (VSS-private actors) policies can contribute positively to biodiversity protection. It examines the degree to which VSS organizations' current connections with one another, with other non-governmental parties, and with intergovernmental treaties, laws, and organizations allow for collectively advancing biodiversity goals. The study first draws from datasets from Fransen, which focused on VSS organizations governing global agro-commodity chains, such as coffee, tea, cocoa, sugar, palm oil, cotton, soy, and flowers. Information from this dataset is complemented with data on these commodities from the International Institute for Sustainable Development Sustainability Standards Initiative report on standards and biodiversity, the International Trade Centre's Standards Map data, and the study by Tayleur et al. [12] on the location of agriculture-focused VSS organization standard-compliant areas. Combining these four data sources allowed the authors to analyze 11 relevant VSS focused on agro-commodities and how they interact with other actors, most notably public organizations. To gauge their significance, authors rank VSS organizations according to three criteria: the amount of hectares covered by a VSS in terms of standard-compliant areas; the proximity of standard-compliant areas to so-called biodiversity hotspots, i.e., regions with significant biodiversity under threat of destruction; and the stringency of biodiversity criteria in the implementation of a given VSS. They conclude that only a few VSS organizations are in a promising position to potentially contribute through their policy-making to biodiversity protection goals. At the same time, based on the analysis of network positions, VSS organizational links to relevant biodiversity actors and institutions are still quite scarce, signaling that their ability to engage in collaborative policy-making and policy exchange with relevant biodiversity policymakers is, at present, limited. Currently, most of these VSS organizations have relatively few ties with the relevant governmental and intergovernmental biodiversity policymakers. At present, their policy networks, in terms of actors, reflect an orientation towards nongovernmental rather than governmental organizations, and, substantively, an orientation towards developmental rather than environmental protection issues.

Taken together these contributions provide insights into the different aspects of the design of public-private partnerships and how their effectiveness might be affected. First, there is a question as to what degree partnerships internalize and operationalize norms and standards in relation to the sustainability which they want to pursue. Second, there is an important component of public-private partnerships which addresses who is involved in a public-private partnership, how they are governed, and which inter-organizational relationships are established. Third, public-private partnerships interact with other parties, rule-takers or rule-targets. This can have different forms and different outcomes. Finally, public-private partnerships operate in a broader context of inter-organizational relations within a specific policy-field. How they operate in a complex web of policy-actors will also determine their effectiveness.

Funding: Work on this special issue was made possible by funding from the Belgian Ministry of Foreign Affairs-Directorate-General for Development Cooperation and VLIR (Flemish Inter-university Council) under the KLIMOS Project.

Conflicts of Interest: The author declares no conflict of interest. 


\section{References}

1. Rosenau, J.R. Governance in the Twenty-first Century. Glob. Gov. 1995, 1, 13-43.

2. Lambin, E.F.; Meyfroidt, P.; Rueda, X.; Blackman, A.; Börner, J.; Cerutti, P.O.; Dietsch, T.; Jungmann, L.; Lamarque, P.; Lister, J.; et al. Effectiveness and Synergies of Policy Instruments for Land Use Governance in Tropical Regions. Glob. Environ. Chang. 2014, 28, 129-140. [CrossRef]

3. Lambin, E.; Thorlakson, T. Sustainability Standards: Interactions between private actors, civil society and governments. Annu. Rev. Environ. Resour. 2018, 43, 369-393. [CrossRef]

4. Eberlein, B.; Abbott, K.; Black, J.; Meidinger, E.; Wood, S. Transnational Business Governance Interactions: conceptualization and framework for analysis. Regul. Gov. 2014, 8, 1-21. [CrossRef]

5. Abbott, K.W.; Levi-faur, D.; Snidal, D. Theorizing Regulatory Intermediaries. Ann. Am. Acad. Political Soc. Sci. 2017, 670, 14-35. [CrossRef]

6. Marx, A.; Wouters, J. Redesigning enforcement in private labor regulation. Will it work? Int. Labor Rev. 2016, 155, 435-459. [CrossRef]

7. Marx, A. Varieties of Legitimacy: A Configurational Institutional Design Analysis of Eco-labels. Innov. Eur. J. Soc. Sci. Res. 2013, 26, 268-287. [CrossRef]

8. Mert, A. Sustainable Development Partnerships in the UN System. In Networks for Prosperity: Advancing Sustainability through Partnerships; UNIDO/University of Leuven: Leuven, Belgium, 2015; pp. 55-67.

9. Pattberg, P.; Chan, M.; Mert, A.; Biermann, F. Public-private Partnerships for Sustainable Development: Emergence, Influence and Legitimacy; Edward Elgar: Cheltenham, UK, 2012.

10. Ostrom, E. Governing the Commons; Cambridge University Press: Cambridge, UK, 1990.

11. Uzzi, B. The Sources and Consequences of Embeddedness for the Economic Performance of Organizations: The Network Effect. Am. Sociol. Rev. 1996, 61, 674-698. [CrossRef]

12. Tayleur, C.; Balmford, A.; Buchanan, G.M.; Butchart, S.H.; Walker, C.C.; Ducharme, H.; Tracewski, L. Where are commodity crops certified, and what does it mean for conservation and poverty alleviation? Boil. Conserv. 2018, 217, 36-46. [CrossRef]

(C) 2019 by the author. Licensee MDPI, Basel, Switzerland. This article is an open access article distributed under the terms and conditions of the Creative Commons Attribution (CC BY) license (http:/ / creativecommons.org/licenses/by/4.0/). 